\title{
Trade, Infrastructure, and Roadways in Europe and Central Asia: New Empirical Evidence
}

\author{
Ben Shepherd \\ The World Bank \\ John S. Wilson \\ The World Bank
}

\begin{abstract}
Infrastructure quality is a crucial determinant of trade. To assess the importance of regional infrastructure externalities, we use detailed overland transit information from an original road network database. Gravity model simulations suggest that an ambitious but feasible road upgrade could increase trade by 50\% over baseline, exceeding the expected gains from tariff reductions or trade facilitation programs of comparable scope. Cross-country spillovers due to overland transit are very large: total intraregional trade could be increased by $30 \%$ by upgrading roads in just three countries-Albania, Hungary and Romania. These results bolster the case for regional coordination of infrastructure investments.
\end{abstract}

- JEL classification: F13, F15, H54

- Keywords: International Trade, Europe and Central Asia, Road Transport, Trade Facilitation, Gravity Model

\footnotetext{
*Corresponding address: The authors are respectively Consultant and Lead Economist, DECRG-Trade, The World Bank, MSN MC3-303, 1818 H. St. NW, Washington DC, 20433, USA,

Tel. +1-202-458-8526, Fax +1-202-522-1159, bshepherd@worldbank.org (corresponding author) and jswilson@worldbank.org.

@2007-Center for International Economics, Sejong Institution, All Rights Reserved.
} 


\section{Introduction}

In this paper, we show that better roads are strongly associated with larger trade flows within the Eastern Europe and Central Asia region (ECA). Simulation results demonstrate that the benefits for ECA from upgrading its road network may well be greater than from tariff reforms or customs streamlining programs of comparable ambition. This is the case even when the up front costs of road improvement are netted out. We also find evidence of the need for regional coordination of road network upgrades. ${ }^{1}$ This is due to large cross-country spillovers stemming from transit effects. Our results indicate that road investments in Albania, Hungary and Romania are likely to have particularly large trade payoffs for the region as a whole.

We focus on road transport because of its particular importance in the ECA region (Molnar and Ojala 2003; ADB 2006; Grigoriou 2006). ${ }^{2}$ Part of this importance comes from the fact that eleven of the 27 countries we study are landlocked. The available empirical evidence suggests that being landlocked adds significantly to the cost of trading internationally (Limão and Venables, 2001; Raballand 2003; Grigoriou 2006). Exporting firms rely not only on the quality of infrastructure provided by their home governments, but also on that of neighboring countries through which goods must transit. Because of this, the relationship between road quality and trade may not be entirely linear: for example, upgrades in important transit countries or resolution of regional bottlenecks could have impacts well beyond the individual countries concerned. Our results provide strong support for this view.

An important aspect of our paper is its comparative outlook. We are primarily interested in identifying the intraregional trade benefits that can come from improved roads. We also want, however, to compare them with what is available from different policy approaches, such as tariff reductions or more streamlined customs procedures (largely an issue of "trade facilitation" as reflected in World

\footnotetext{
${ }^{1}$ This point also emerges from the theoretical literature on regional coordination of infrastructure policies: e.g., Bougheas et al. (2003), Egger and Falkinger (2006), and Schiff and Winters (2002).

${ }^{2}$ The European Union provides trade data disaggregated by transport mode for imports originating in countries outside the EU-25 (http://fd.comext.eurostat.cec.eu.int/xtweb/). In 2003, road transport covered around 30\% of EU-25 imports from countries in our sample (excluding trade arriving through fixed installations, such as pipelines). Maritime transport made up most of the remainder (55\% of the total), with air and rail representing just $4 \%$ each. For intra-regional trade amongst our sample countries, no such data are available. However, we expect the proportion of road transport to be higher than $30 \%$, given that a number of sample countries lack access to the sea.
} 
Trade Organization disciplines). The relative costs and benefits of these options are of direct interest to policymakers. At the same time, there is mounting empirical evidence that in the current environment of historically low tariff levels, "traditional" trade policy accounts for an increasingly small proportion of overall trade costs (Anderson and Van Wincoop 2004). This analysis suggests that the impact of policy reform in the areas of trade-related infrastructure and trade facilitation might be correspondingly greater. Our results support this conclusion.

Against this background, the empirical literature has produced a number of model-based evaluations of the sensitivity of trade flows to infrastructure and trade facilitation. Studies of general scope such as Bougheas et al. (1999), Wilson et al. (2005) and Francois and Manchin (2006) use the gravity model to show that improvements along those dimensions are associated with increased trade flows. Another strand of the trade facilitation literature has emphasized the importance of time delays (Djankov et al. 2006; Nordås et al. 2006). Meanwhile, the results in Limão and Venables (2001) demonstrate that infrastructure plays an important role in determining transport costs, and thereby impacts trade flows. Nordås and Piermartini (2004) and Grigoriou (2006) arrive at similar conclusions. In particular, the latter paper shows that the infrastructure of neighboring countries is important for landlocked Central Asian economies, due to transit effects.

Two recent papers deal more specifically with road infrastructure. The first of them, Coulibaly and Fontagné (2006), focuses on West Africa. The authors find that a composite measure of road quality in the importing and exporting countries has a positive and statistically significant effect on trade. Transit effects are also important, with the authors using a count of the number of borders crossed as a proxy. By contrast, Buys et al. (2006) examine road network quality across the whole of Sub-Saharan Africa (SSA). They use detailed road transport data to construct measures of international distance on an overland basis. They then build up a multi-dimensional measure of road quality, which is aggregated taking proper account of transit effects. Results from their gravity model show that network quality has a significant impact on intra-regional trade, while simulations suggest that the benefits of a road upgrade are very substantial: around $\$ 250$ bn over 15 years. The trade benefits far outweigh the costs, which include an initial investment of the order of $\$ 20 \mathrm{bn}$ and yearly maintenance of $\$ 1 \mathrm{bn}$.

Our paper builds on and extends this literature in five main ways. In terms of substance, our analysis incorporates a new ECA road distance database similar to the one used by Buys et al. (2006) in the SSA context (Section 2). It allows us to 
identify road transit routes in detail, and to construct bilateral road quality indicators based on actual distances traveled in the exporting, importing and transit countries (Section 3). Secondly, our data and gravity model (Sections 4-5) allow us to simulate the trade impacts of road upgrades in different countries, taking account of cross-border spillovers due to overland transit. The risk of endogeneity of our road quality measures to bilateral trade is much smaller than in previous work, since transit effects mean that infrastructure matters not just in the exporting and importing countries, but also in those countries situated between them which are not directly involved in the bilateral trading relationship. Thirdly, our model includes policy variables covering applied tariffs and trade facilitation, in addition to road network quality. This enables a comparison of the relative impacts of different reform scenarios (Section 6). On the methodological front, we use the "theoretical" gravity model specification due to Anderson and Van Wincoop (2003, 2004). Fixed effects are used to take account of unobservable country- and sector-specific factors, including multilateral resistance. Finally, to ensure that our results are robust to the presence of zero trade flows in the dataset, we use a variation on the Poisson PseudoMaximum Likelihood approach of Santos Silva and Tenreyro (2006).

\section{Mapping Road Networks in Europe and Central Asia}

As defined in this paper, the ECA region covers 27 countries stretching from the Czech Republic in the West to Russia (Siberia) in the East, and from Turkmenistan in the South to the Baltic States and Russia in the North. ${ }^{3}$ Anecdotal evidence suggests that the road network in this area is extensive, but of variable quality. This observation is particularly true in those countries where the post-Communist transition has been long and difficult. (See Molnar and Ojala 2003; ADB 2006; and Grigoriou 2006 for further details.)

Computerized maps and spatial analysis software make it possible to develop a detailed picture of road transport routes in the ECA region, as Buys et al. (2006) have done for SSA. We construct minimum-distance routes connecting 138 cities, i.e. all regional cities with a year 2000 population of over 300000 people. In all, we have 9453 inter-city routes along 2411 individual arcs. For each route, we are

\footnotetext{
${ }^{3}$ The complete list of countries we analyze is as follows: Albania, Armenia, Azerbaijan, Belarus, Bosnia and Herzegovina, Bulgaria, Croatia, Czech Republic, Estonia, Georgia, Hungary, Kazakhstan, Kyrgyz Republic, Latvia, Lithuania, Macedonia FYR, Moldova, Poland, Romania, Russian Federation, Serbia and Montenegro, Slovak Republic, Slovenia, Tajikistan, Turkmenistan, Ukraine and Uzbekistan.
} 
able to identify the exact road distance traveled in each of the sample countries. For instance, the minimum distance route from Prague to Moscow includes $128.6 \mathrm{~km}$ of road travel in the Czech Republic, $723.6 \mathrm{~km}$ in Poland, $547.2 \mathrm{~km}$ in Belarus and finally $454.4 \mathrm{~km}$ in Russia.

We will be analyzing international trade data in the remainder of this paper. We need, therefore, to aggregate our intercity road distance data to the country level. To do that, we adopt the convention that the distance between two countries will be treated as the unweighted mean of the minimum road distances between all cities for which we have data in those two countries. This is the same approach as in Buys et al. (2006). ${ }^{4}$

As a check on the reliability of our international distance measure, we compare it with the CEPII distance database (Mayer and Zignago 2006). The most commonly used CEPII measure expresses the distance between two countries as the great circle distance between their respective largest cities. Over the full sample, we find a correlation coefficient equal to 0.93 . However, at long distances (greater than $3000 \mathrm{~km})$ the relationship between the two series is substantially weaker $(\rho=0.66)$. The CEPII measure is systematically lower than ours over long bilateral distances. We take this as indicating that while the great circle approximation is reasonable for short overland distances, it loses much of its relevance as those distances grow. A detailed mapping is therefore particularly important for long international routes, such as those we are dealing with in the ECA context.

One potential drawback with our approach — which might also explain part of the difference between our measures and CEPII's - stems from the considerable cross-country variation that our network map displays in terms of detail. The minimum population threshold that we have chosen results in 16 out of 27 countries being represented by a single city, while the largest country (Russia) is represented by 63 cities. At first glance, it seems plausible that Russia might therefore exert an undue influence on our results. However, even with Russia excluded from the sample, the pattern identified above with respect to the CEPII distance measure still stands (full sample $\rho=0.94$; for distances greater than $3000 \mathrm{~km}, \rho=0.62$ ). Further, we find below that exclusion of Russia from the estimation sample in fact has little bearing on the estimated coefficients. We are therefore confident that our population criterion, while necessarily arbitrary, strikes an acceptable balance between detail and tractability.

\footnotetext{
${ }^{4}$ Weighting distances by city population, or using the median rather than the mean, does not change our results.
} 


\section{Measuring the Quality of Road Networks}

The literature cited above generally uses the percent of paved roads in a country as a proxy for road quality (Limão and Venables, 2001; Coulibaly and Fontagné, 2006; and Grigoriou, 2006). Buys et al. (2006), by contrast, also include GDP per capita and a corruption indicator. ${ }^{5}$ Such an approach is valuable insofar as it highlights the fact that upgrading road quality is not just about bitumen, but also requires maintenance capacity and the ability to control unofficial payments. However, aggregating all three dimensions into a single composite indicator makes it difficult to relate regression coefficients to specific policy actions. In particular, the relative importance of each dimension in relation to the others is determined by the researcher's priors, and not by the data themselves. The desire to map our results directly to policy space motivates our decision to limit our consideration of "quality" to the percent paved roads criterion.

In constructing a road quality measure, we compare data from different sources to resolve (usually minor) disagreements amongst them. We have, however, found examples of apparently spurious time-series variation in percent paved roads data. Such instances appear to be related to definitional changes that can significantly alter the apparent percent of paved roads, even though no physical changes have in fact taken place. Our preferred measures correct for such problems in a small number of cases. ${ }^{6}$ We believe that our measures represent a realistic approximation.

One important advantage of our road distance mapping approach is that it enables us to produce detailed measures of bilateral road quality that take full account of transit effects. We can consider road quality in third countries, not just the exporter and importer (cf. Nordås and Piermartini 2004). We can also use actual transit distances to weight road quality in each country along the route, rather than using an approximation such as a count of the number of border crossings (cf. Coulibaly and Fontagné 2006).

We construct two measures of road quality. The first is a distance weighted average (paved_ave). We construct it using the percent of paved roads in the exporting and

\footnotetext{
${ }^{5}$ The Buys et al. (2006) indicator $Q_{j}$ combines the percent of paved roads $\left(\mathrm{P}_{j}\right)$, per capita $\operatorname{GDP}\left(G_{j}\right)$ and the World Bank's Country Policy and Institutional Capacity Index $\left(C_{j}\right)$ such that $Q_{j}=P_{j}^{\alpha_{1}} G_{j}^{\alpha_{2}} C_{j}^{\alpha_{3}}$. Imposing slightly increasing returns, the alpha parameters are set to $\alpha_{1}=0.8, \alpha_{2}=0.2$ and $\alpha_{3}=0.2$.

${ }^{6}$ Our preferred measures accord with the World Development Indicators for all countries except Belarus, Lithuania, Romania and the Russian Federation. For those countries, we use data from World Road Statistics and the CIA World Fact Book, cross-checked with World Bank experts.
} 
importing countries, as well as in all transit countries along the set of minimum distance routes used to calculate international distances as set out above. The paved roads data are weighted in each case by the proportion of the total distance traveled in each country. Our second measure (paved_min) is calculated using the same information, but taking the minimum percent of paved roads observed across the exporting, importing and transit countries. The purpose of this measure is to help identify bottlenecks and assess the potential for cross-country infrastructure spillovers. An incidental benefit of our approach is that our quality measures are unlikely to suffer unduly from endogeneity to bilateral trade flows, since they depend also on policy decisions by countries not involved in a given bilateral relationship.

Interestingly, we find strong geographical concentration (65\%) of paved_min scores in just three countries: Albania, Hungary and Romania. To the extent that paved_min is a significant determinant of bilateral trade, this finding suggests that improved road quality in those three countries is likely to impact a substantial number of third-country trade flows.

\section{Model Description and Data}

As noted at the outset, our primary interest is in assessing the impact of road quality on intraregional trade. We would also like to compare that impact to what can be had through tariff reductions and improved trade facilitation. To do that, we will use a standard tool of empirical international trade, namely the gravity model. Our specification is based on the micro-founded gravity model due to Anderson and Van Wincoop (2003, 2004):

$$
\begin{aligned}
\log \left(X_{i j}^{k}\right) & =\log \left(E_{j}^{k}\right)+\log \left(Y_{i}^{k}\right)-\log \left(Y^{k}\right)+\left(1-\sigma_{k}\right) \log \left(t_{i j}^{k}\right) \\
& -\left(1-\sigma_{k}\right) \log \left(p_{j}^{k}\right)-\left(1-\sigma_{k}\right) \log \left(\Pi_{i}^{k}\right)+\varepsilon_{i j}^{k}
\end{aligned}
$$

Where: $X_{i j}^{k}=$ Exports from country $i$ to country $j$ in sector $k$; $Y_{i}^{k}=$ Output of country $i$ in sector $k ; E_{j}^{k}=$ Expenditure of country $j$ in sector $k ; Y^{k}=$ Aggregate (world) output in sector $k ; s_{k}=$ Elasticity of substitution in sector $k ; t_{i j}^{k}=$ Trade costs facing exports from country $i$ to country $j$ in sector $k ;\left(P_{j}^{k}\right)^{1-\sigma_{k}}=\sum_{i=1}^{N} \Pi_{i}^{\sigma_{k}-1} \omega_{i}^{k}\left(t_{i j}^{k}\right)^{1-\sigma_{k}} ;\left(\Pi_{j}^{k}\right)^{1-\sigma_{k}}=$ $\left(\Pi_{j}^{k}\right)^{1-\sigma_{k}}=\sum_{i=1}^{N} P_{j}^{\sigma_{k}-1} \omega_{j}^{k}\left(t_{i j}^{k}\right)^{1-\sigma_{k}} ; \omega_{i}^{k}=$ Country i's output share in sector $k ; \omega_{j}^{k}=$ Country $j$ 's expenditure share in sector $k$; $\varepsilon_{i j}^{k}=$ Random error term, satisfying the 
usual assumptions.

As is well known, the most important innovation of this model is its inclusion of the "resistance" or "remoteness" terms $P_{j}^{k}$ and $\Pi_{i}^{k}$. Inward resistance $P_{j}^{k}$ captures the fact that $\mathrm{j}$ 's imports from $i$ depend on trade costs across all suppliers. Outward resistance $\Pi_{i}^{k}$, by contrast, captures the dependence of exports from $i$ to $j$ on trade costs across all importers.

In applied work with (1), bilateral trade costs $t_{i j}^{k}$ need to be specified in terms of observables. We postulate:

$$
t_{i j}^{k}=d_{i j}^{\rho} \tau_{j i}^{\theta} \prod_{m=1}^{M}\left(b_{m}^{z_{i j}^{k, m}}\right)
$$

Where: $\rho=$ elasticity of exports with respect to distance; $d_{i j}=$ distance between countries $i$ and $j ; b_{m}=$ set of $m$ constants; $z_{i j}=$ set of observable bilateral determinants of trade costs.

Combining (1) and (2) gives our baseline gravity model:

$$
\begin{aligned}
\log \left(X_{i j}^{k}\right) & =\log \left(E_{j}^{k}\right)+\log \left(Y_{i}^{k}\right)-\log \left(Y^{k}\right)+\left(1-\sigma_{k}\right)\left[\rho \log \left(d_{i j}\right)+\sum_{m=1}^{M}\left(\log \left(b_{m}\right)\right) z_{i j}^{k, m}\right] \\
& -\ldots-\left(1-\sigma_{k}\right) \log \left(p_{j}^{k}\right)-\left(1-\sigma_{k}\right) \log \left(\Pi_{i}^{k}\right)+\varepsilon_{i j}^{k}
\end{aligned}
$$

The resistance terms $P_{j}^{k}$ and $\Pi_{i}^{k}$ are not directly observable. We will account for them using fixed effects. In a panel data context, Baldwin and Taglioni (2006) have recently shown that proper specification of the fixed effects version of (3) has given rise to considerable confusion in the applied literature. When estimating over a single year, (3) should, strictly speaking, include fixed effects in the exporter-sector, importer-sector and sector dimensions. In addition, given that the elasticity of substitution $\sigma_{k}$ varies across sectors, it is necessary to allow the reduced form coefficients in the trade cost function to do likewise. A strict derivation therefore suggests the following estimable form for (3):

$$
\begin{aligned}
\log \left(X_{i j}^{k}\right) & =\delta_{i}^{k}+\delta_{j}^{k}+\delta_{k}+\sum_{k=1}^{K} \beta_{1}^{k} \log \left(\text { dist }_{i j}\right)+\sum_{k=1}^{K} \beta_{2}^{k} \log (\text { paved_ave }) \\
& +\sum_{k=1}^{K} \beta_{3}^{k} \log (\text { paved_min })+\ldots+\sum_{k=1}^{K} \beta_{4}^{k} \log (1+\text { tariff })
\end{aligned}
$$




$$
\begin{gathered}
+\sum_{k=1}^{K} \beta_{5}^{k} \log (\text { docs })+\sum_{k=1}^{K} \beta_{6}^{k} \text { border }+\sum_{k=1}^{K} \beta_{7}^{k} \text { colony } \\
+\sum_{k=1}^{K} \beta_{8}^{k} \text { language }+\varepsilon_{i j}^{k}
\end{gathered}
$$

Depending on the size of the dataset, it may prove difficult to identify all coefficients in (4) due in particular to lack of variation in the exporter-sector or importer-sector dimensions. We therefore propose a simplification in which trade cost elasticities are assumed to be constant across sectors, and country-sector fixed effects are taken to be subsumed by country fixed effects. The resulting estimation equation (5) uses fewer degrees of freedom than (4), but can be expected to provide a reasonable approximation when cross-sectoral variation is not too strong.

$$
\begin{aligned}
\log \left(X_{i j}^{k}\right) & =c+\delta_{i}+\delta_{j}+\delta_{k}+\beta_{1} \log \left(\text { dist }_{i j}\right)+\beta_{2} \log (\text { paved_ave }) \\
& +\beta_{3} \log (\text { paved_min })+\ldots+\beta_{4} \log (1+\text { tariff })+\beta_{5} \log (\text { docs }) \\
& +\beta_{6} \text { border }+\beta_{7} \text { colony }+\beta_{8} \text { language }+\varepsilon_{i j}
\end{aligned}
$$

Our data and sources are set out in detail in Table 1. For bilateral trade, we use the value of 2003 imports by BEC 1-digit sector, taken from the WITS database. Whenever import data are missing, we use export (mirror) data. Trade cost dummies based on geographical and historical factors (contiguity, colonization and common language) are drawn from the CEPII distance database (Mayer and Zignago 2006). Distance is measured using average intercity road distances obtained by computer mapping, as set out above. Paved_ave and Paved_min refer to our measures of average and minimum road quality. Our tariff variable is drawn from effective applied tariffs as recorded in the WITS-TRAINS database. ${ }^{7}$ For trade facilitation, we use data from the 2006 Doing Business Report (World Bank, 2006) on the number of documents required to export and import, summing across

\footnotetext{
${ }^{7}$ We use the simple average tariff when aggregating to the BEC 1-digit level. Use of the trade weighted average does not affect our results.

${ }^{8}$ Due to lack of data availability, we use customs formalities in 2005 as a proxy for 2003. Similarly, when TRAINS data are missing for a given year, we take the most recent available data prior to 2003.

${ }^{9}$ The results of Djankov et al. (2006) indirectly support this argument. Those authors instrument for trading time using two related variables, namely the number of signatures required to export and import. Their model is overidentified and does not reject the relevant restriction, which suggests that the proposed instruments are valid.
} 
Table 1. Variables and sources

\begin{tabular}{|c|c|c|c|}
\hline Variable & Description & Year & Source \\
\hline Border $_{i j}$ & Dummy variable equal to 1 if countries $i$ and $j$ share a common land border & NA & Mayer \& Zignago (2006) \\
\hline Colony $_{\mathrm{ij}}$ & Dummy variable equal to 1 if countries $i$ and $j$ have ever had a colonial link & NA & Mayer \& Zignago (2006) \\
\hline Comlang_Ethno $\mathrm{ij}_{\mathrm{ij}}$ & $\begin{array}{l}\text { Dummy variable equal to } 1 \text { if the same language is spoken by at least } 9 \% \\
\text { of the populations of countries } i \text { and } j\end{array}$ & NA & Mayer \& Zignago (2006) \\
\hline Dist_Cepii $i_{i j}$ & Great circle distance between countries $\mathrm{i}$ and $\mathrm{j}$ & NA & Mayer \& Zignago (2006) \\
\hline Distance_Mean $_{\mathrm{ij}}$ or Dist $\mathrm{Dij}_{\mathrm{ij}}$ & $\begin{array}{l}\text { Distance between countries } \mathrm{i} \text { and } \mathrm{j} \text { calculated as the mean of road distances } \\
\text { between city pairs in those countries }\end{array}$ & NA & Own calculations \\
\hline Docs $_{\mathrm{ij}}$ & $\begin{array}{l}\text { Sum of number of export documents in origin country and number of } \\
\text { import documents in final destination country }\end{array}$ & 2005 & World Bank (2006) \\
\hline Paved_Ave $_{i j}$ & $\begin{array}{l}\text { Average of quality index in origin country } i \text {, destination country } j \text { and all } \\
\text { transit countries (based on road routing), weighted by distance traveled in } \\
\text { each country as a fraction of total distance between } i \text { and } j \text {. }\end{array}$ & 2003 & Own calculations \\
\hline Paved_Min $_{\mathrm{ij}}$ & $\begin{array}{l}\text { Minimum of quality index in origin country } i \text {, destination country } j \text { and all } \\
\text { transit countries (based on road routing) }\end{array}$ & 2003 & Own calculations \\
\hline Tariff $_{\mathrm{ij}}$ & $1+$ Simple average tariff applied by country $\mathrm{j}$ to imports from country $\mathrm{i}$ & 2003 & WITS - UNCTAD TRAINS \\
\hline Trade_k & $\begin{array}{l}\text { Merchandise imports in BEC sector k (aggregated from HS-1996) into } \\
\text { destination country from origin country, in US dollars }\end{array}$ & 2003 & WITS - UN Comtrade \\
\hline Trade0_k & Trade_k with zeros inserted for missing bilateral trade flows & 2003 & $\begin{array}{l}\text { WITS - UN Comtrade and } \\
\text { own calculations }\end{array}$ \\
\hline
\end{tabular}


the exporting and importing countries $($ docs $) .{ }^{8}$ We prefer this measure to the more commonly used indicator of time to export and import (Djankov et al. 2006; Nordås et al. 2006) because it does not suffer from endogeneity to trade flows in the same way: while an unexpectedly large trade flow this year might lead to congestion and thereby a contemporaneous increase in trading time, the same is not true for the number of documents required by customs authorities. ${ }^{9}$ Another appealing feature of our measure is that it bears a close relationship to the core interpretation given to "trade facilitation" at the WTO, which emphasizes the streamlining of trade-related administrative procedures and formalities (Wilson 2005).

\section{Estimation Results}

The first three columns of Table 2 contain our OLS estimates. ${ }^{10}$ The dependent variable is $\log$ (trade), with zero or missing observations simply dropped from the dataset; this is an issue we return to below. We estimate three different models using different combinations of paved_ave and paved_min in order to gauge the robustness of our results to variable exclusion. All three models perform well, with $\mathrm{R}^{2}$ of around $62 \%$. All estimated coefficients carry the expected signs and have economically reasonable magnitudes. Except in the case of paved_ave, coefficient estimates are quite stable across specifications. The distance elasticity is greater than 2 in absolute value in all three models, which is stronger than the central tendency of the gravity literature (around 0.9 according to the meta-analysis of Disdier and Head 2005). We put the difference down to three factors. Firstly, we use overland distances and not the more common great circle measures. Secondly, our data are disaggregated at the sectoral level, whereas many gravity models use total trade. Thirdly, our sample covers just one geographic region, in which it is conceivable that road distance plays a particularly important role, for the reasons set out above.

Only distance, paved_min, tariffs and common language are statistically significant at conventional levels. A $1 \%$ improvement in paved_min is associated with a $0.6 \%$ increase in trade, while a $1 \%$ cut in applied tariffs increases trade by $3.5 \%$ (evaluated at the approximate sample mean of $8 \%$ ). Even though the estimated coefficients for paved_ave and docs are not statistically significant, we still regard them as economically significant: a $1 \%$ improvement in average road quality is associated with a $0.2 \%$ to $0.6 \%$ increase in trade, while a similar percentage

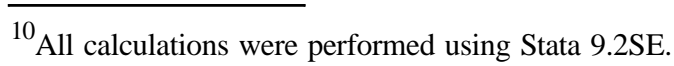


Table 2. Regression results for gravity equation (5) using BEC 1-digit data, 2003

\begin{tabular}{|c|c|c|c|c|c|c|c|c|c|}
\hline \multirow{2}{*}{ Variable } & \multicolumn{3}{|c|}{ OLS } & \multicolumn{3}{|c|}{ Poisson } & \multicolumn{3}{|c|}{ NB2 } \\
\hline & Model 1 & Model 2 & Model 3 & Model 1 & Model 2 & Model 3 & Model 1 & Model 2 & Model 3 \\
\hline \multirow{2}{*}{ ldist } & $-2.08 * * *$ & $-2.19 * * *$ & $-2.06 * * *$ & $-1.32 * * *$ & $-1.36 * * *$ & $-1.40 * * *$ & $-1.74 * * *$ & $-1.86 * * *$ & $-1.68 * * *$ \\
\hline & 0.15 & 0.14 & 0.14 & 0.18 & 0.18 & 0.17 & 0.17 & 0.16 & 0.18 \\
\hline \multirow{2}{*}{ lpaved_ave } & 0.18 & 0.56 & & $1.37 * * *$ & $1.50 * * *$ & & $0.79 *$ & $1.21 * * *$ & \\
\hline & 0.44 & 0.41 & & 0.52 & 0.52 & & 0.40 & 0.38 & \\
\hline lpaved_min & $0.56 * * *$ & & $0.59 * * *$ & 0.20 & & $0.33^{*}$ & $0.60 * * *$ & & $0.74 * * *$ \\
\hline \multirow{2}{*}{ ltariff } & $-4.72 * * *$ & $-4.76 * * *$ & $-4.73 * * *$ & $-6.71 * * *$ & $-6.97 * * *$ & $-6.44 * * *$ & $-4.03 * * *$ & $-3.96 * * *$ & $-4.05 * * *$ \\
\hline & 0.91 & 0.91 & 0.91 & 2.08 & 2.08 & 2.10 & 0.78 & 0.79 & 0.78 \\
\hline \multirow{2}{*}{ ldocs } & -3.06 & -2.39 & -3.19 & 2.40 & 2.41 & 2.15 & $-4.03 *$ & -3.12 & $-4.79 * *$ \\
\hline & 2.47 & 2.48 & 2.47 & 3.41 & 3.26 & 3.38 & 2.21 & 2.30 & 2.23 \\
\hline border & 0.24 & 0.24 & 0.25 & 0.19 & 0.17 & 0.20 & 0.01 & 0.02 & 0.04 \\
\hline comlang_ethno & 0.33 & 0.34 & 0.32 & 0.22 & 0.22 & 0.25 & 0.25 & 0.25 & 0.25 \\
\hline \multirow{2}{*}{ constant } & $24.60 * * *$ & $26.59 * * *$ & $25.47 * * *$ & 3.34 & 9.71 & 9.81 & $26.48 * * *$ & $26.72 * * *$ & $30.91 * * *$ \\
\hline & 7.54 & 8.29 & 7.30 & 9.68 & 7.67 & 9.45 & 6.75 & 5.92 & 6.64 \\
\hline Observations & 2440 & 2440 & 2440 & 2559 & 2559 & 2559 & 2559 & 2559 & 2559 \\
\hline $\mathrm{R}^{2} /$ Pseudo $\mathrm{R}^{2}$ & 0.62 & 0.62 & 0.62 & 0.78 & 0.78 & 0.78 & 0.03 & 0.03 & 0.03 \\
\hline Model F/ $\chi^{2}$ & $58.99 * * *$ & $58.19 * * *$ & $59.30 * * *$ & $16491.58 * * *$ & $17830.7^{* * *}$ & $17733.07 * * *$ & $3761.55^{* * * *}$ & $3574.03 * * *$ & $3677.03 * * *$ \\
\hline
\end{tabular}

a. Dependent variable is $\log ($ trade) in columns 1-3, and trade0 in columns 4-9.

b. All models include fixed effects by exporter, importer and sector

c. Robust standard errors (adjusted for clustering by country-pair) are in italics.

d. Statistical significance at the $10 \%, 5 \%$ and $1 \%$ levels is indicated by $* * *$ and $* * *$ respectively. 
reduction in the number of export and import documents is associated with a $2.4 \%$ to $3.2 \%$ increase in trade. Based on these estimates, we tentatively conclude that improved road quality, lower tariffs and better trade facilitation are all associated with stronger bilateral trade.

To be sure that this result holds, we need to deal more carefully with the issue of zero or missing trade flows. In our case, around 1500 observations (nearly onethird of the potential dataset) fall into that category. Unfortunately, we are also missing data for applied tariffs and trade facilitation. This means that in terms of our effective sample, i.e. the number of observations for which data are available across all variables, the zero problem in fact only affects 159 observations. Although this is just $6 \%$ or so of the effective sample, we still believe it is important to ensure that our results are robust in this sense.

Our approach to this problem follows Santos Silva and Tenreyro (2006). ${ }^{11}$ First, we express (5) in non-linear form (i.e., prior to taking logarithms):

$$
X 0_{i j}^{k}=\exp \left[\begin{array}{l}
c+\delta_{i}+\delta_{j}+\delta_{k}+\beta_{1} \log \left(\text { dist }_{i j}\right)+\beta_{2} \log (\text { paved_ave }) \\
+\beta_{3} \log (\text { paved_min })+\ldots+\beta_{4} \log (1+\text { tariff })+\beta_{5} \log (\text { docs }) \\
+\beta_{6} \text { border }+\beta_{7} \text { colony }+\beta_{8} \text { language }
\end{array}\right]+\omega_{i j}^{k}
$$

The notation $X 0_{i j}^{k}$ is designed to emphasize the fact that the trade flow data include zeros. The essential difference between (5) and (6) relates to the error term, which we have relabeled $\omega_{i j}^{k}$ in (6). Equation (5) assumes that the error is additive in a loglinear specification, or alternately that $\exp \left(\varepsilon_{i j}^{k}\right)$ is multiplicative in the original nonlinear specification. On the other hand, equation (6) more naturally assumes that the error is additive in the original non-linear specification. If (6) represents the "true" model, then the OLS estimator derived by log-linearization will generally be inconsistent (see Santos Silva and Tenreyro 2006 for details).

\footnotetext{
${ }^{11}$ An alternative to their approach is the Heckman (1979) sample selection model. Francois and Manchin (2006) and Helpman et al. (2007) apply it in the gravity context. Its main advantage is that it estimates the impact of standard gravity variables both on trade flows, and on the propensity to export. It can also be connected to fixed and variable trade costs in the context of trade models with increasing returns to scale. However, it is desirable - albeit often difficult to implement in practice-for such models to be over-identified via an exclusion restriction in the outcome equation (Davidson and MacKinnon, 2004, p. 489). Such a restriction is difficult to come by in the trade context, since it requires a variable that impacts trade propensity but not (conditional) trade flows. Francois and Manchin (2006) therefore do not over-identify their model. The model in Helpman et al. (2007) is over-identified, but at the price of a large reduction in sample size due to limited data availability for the excluded variable (costs of establishing a business). We prefer the Santos Silva and Tenreyro (2006) approach since it does not suffer from this identification problem.
} 
The first order conditions for estimation of (6) by weighted nonlinear least squares are identical to those for maximum likelihood estimation using the Poisson model for count data (Gourieroux et al. 1984; Davidson and MacKinnon 2004). Estimated coefficients from Poisson can still be interpreted as elasticities, as under log-linearized OLS.

Although the Poisson estimator can still be consistent under alternative distributional assumptions (i.e., it is a pseudo-maximum likelihood estimator), we also apply a Negative Binomial estimator (NB2 in the terminology of Cameron and Trivedi 2001) that allows for overdispersion in the data and may therefore provide a better fit in this case. First order conditions for maximum likelihood estimation of the NB2 model are again equivalent to weighted nonlinear least squares estimation of (6). However, the NB2 model puts less weight on large observations than does Poisson, the difference between the two depending on the size of the NB2 overdispersion parameter (estimated from the data). In the limiting case of no overdispersion (i.e., $\alpha=0$ ), the NB2 model collapses to Poisson and both estimation methods therefore apply the same weighting system. ${ }^{12}$

Columns 4-6 of Table 2 report estimates using the Poisson model, and columns 7-9 show results for the NB2 model. The overdispersion parameter is estimated in all three NB2 models to be 3.0. A likelihood ratio test of the (unrestricted) NB2 model against the (restricted) Poisson strongly rejects the null for all three specifications $\left(\chi^{2}=9.3 \mathrm{e} 10\right.$ for models 1 and $2, \chi^{2}=9.5 \mathrm{e} 10$ for model 3 , prob. $\left.=0.00\right)$. We conclude that the NB2 model is to be preferred over Poisson, and our discussion of results will therefore focus on the former.

As for the OLS case presented above, we find that coefficient estimates (except for colonization) have the expected signs and economically sensible magnitudes. The coefficient on distance has fallen somewhat in absolute value-an effect also noted by Santos Silva and Tenreyro (2006) — and all policy variables are now significant at the $10 \%$ level. The coeffcients on tariffs and export/import documents are respectively a little weaker and stronger than those obtained with OLS. While paved_min enters with almost the same elasticity as under OLS, paved_ave is considerably stronger. In general, coefficient estimates are quite stable across specifications, although paved_ave and docs exhibit some variance according to

\footnotetext{
${ }^{12}$ Cravino et al. (2006) and Soloaga et al. (2006) also use the NB2 model to estimate gravity models of foreign investment and trade flows respectively. In their Monte Carlo simulations, Santos Silva and Tenreyro (2006) consider the closely related Gamma model, which also downweights large observations compared with Poisson.
} 
Table 3. Sensitivity analysis of gravity model regression results.

\begin{tabular}{|c|c|c|c|c|}
\hline Variable & Bootstrap & $\begin{array}{c}\text { Russia } \\
\text { Excluded }\end{array}$ & $\begin{array}{c}\text { Country-Pair } \\
\text { REs }\end{array}$ & $\begin{array}{c}\text { Country-Sector } \\
\text { FEs }\end{array}$ \\
\hline \multirow{2}{*}{ ldist } & $-1.74 * * *$ & $-1.84 * * *$ & $-1.10 * * *$ & $-2.49 * * *$ \\
\hline & 0.19 & 0.19 & 0.06 & 0.18 \\
\hline \multirow{2}{*}{ lpaved_ave } & 0.79 & $0.81 *$ & -0.19 & 0.34 \\
\hline & 0.52 & 0.45 & 0.22 & 0.39 \\
\hline \multirow{2}{*}{ lpaved_min } & $0.60 * *$ & $0.62 * *$ & $0.25 * *$ & 0.59 *** \\
\hline & 0.25 & 0.27 & 0.11 & 0.19 \\
\hline \multirow{2}{*}{ ltariff } & $-4.03 * * *$ & $-3.33 * * *$ & $-2.31 * * *$ & $-2.77 * * *$ \\
\hline & 0.95 & 0.84 & 0.39 & 0.76 \\
\hline \multirow{2}{*}{ ldocs } & -4.03 & $-3.93^{*}$ & 0.91 & $-3.51^{*}$ \\
\hline & 3.03 & 2.32 & 0.97 & 2 \\
\hline \multirow{2}{*}{ border } & 0.01 & -0.02 & $-0.33 * * *$ & 0 \\
\hline & 0.19 & 0.17 & 0.09 & 0.16 \\
\hline \multirow{2}{*}{ colony } & -0.14 & -0.18 & $0.35 * * *$ & 0.14 \\
\hline & 0.31 & 0.57 & 0.13 & 0.26 \\
\hline \multirow{2}{*}{ comlang_ethno } & $1.09 * * *$ & $1.15 * * *$ & $0.54 * * *$ & $1.08 * * *$ \\
\hline & 0.32 & 0.27 & 0.12 & 0.28 \\
\hline \multirow{2}{*}{ constant } & $36.11 * * *$ & $30.18 * * *$ & 0.75 & $32.91 * * *$ \\
\hline & 10.23 & 6.15 & 2.93 & 5.36 \\
\hline Observations & 2559 & 2290 & 2559 & 2559 \\
\hline
\end{tabular}

a. All models are NB2. Dependent variable is trade0.

b. Models in columns 1-2 include fixed effects by exporter, importer and sector.

c. The model in column 3 includes fixed effects as in b, and random effects by country-pair.

d. The model in column 4 includes fixed effects by exporter-sector, importer-sector and sector.

e. Robust standard errors (adjusted for clustering by country-pair) are in italics in columns 2-4.

f. Bootstrapped standard errors (500 replications, allowing for clustering by country-pair) are in italics in column 1.

the presence or absence of other variables. In terms of magnitude, we find that $1 \%$ improvements in paved_ave and paved_min are associated with trade increases of $0.8 \%$ and $0.6 \%$ respectively. By comparison, $1 \%$ reductions in tariffs and export/ import documents are associated with trade increases of $3.0 \%$ and $4.0 \%$ respectively (evaluated at the sample mean for tariffs).

In Table 3, we present the results of additional robustness checks using our preferred NB2 model. ${ }^{13}$ Exclusion of Russia from the sample (column 2) makes no

\footnotetext{
${ }^{13}$ We provide additional specification and robustness checks in the Appendix (available on request).
} 
significant difference to our results. Bootstrapping (column 1) results in larger standard errors than using asymptotic results. Our variables paved_ave and docs are no longer statistically significant at the $10 \%$ level, but the other variables of interest remain significant. Specifying fixed effects in line with (4), i.e. by importersector, exporter-sector and sector, but imposing constant slope coefficients across sectors, results in a lower (and statistically insignificant) coefficient on paved_ave, but does not result in large changes in the other parameters (column 4). Finally, adding country-pair random effects to (5) to account for possible omission of bilateral

Table 4. Regression results for gravity equation (4) by BEC 1-digit sector, 2003

\begin{tabular}{|c|c|c|c|c|c|c|}
\hline Variable & $\begin{array}{c}\text { Food \& } \\
\text { Beverages }\end{array}$ & $\begin{array}{l}\text { Industrial } \\
\text { Supplies }\end{array}$ & $\begin{array}{c}\text { Fuels \& } \\
\text { Lubricants }\end{array}$ & $\begin{array}{l}\text { Capital } \\
\text { Goods }\end{array}$ & $\begin{array}{c}\text { Transport } \\
\text { Equipment }\end{array}$ & $\begin{array}{l}\text { Consumer } \\
\text { Goods }\end{array}$ \\
\hline \multirow{2}{*}{ ldist } & $-2.50 * * *$ & $-2.23 * * *$ & $-4.92 * * *$ & $-2.01 * * *$ & $-2.81 * * *$ & $-2.45 * * *$ \\
\hline & 0.23 & 0.21 & 0.71 & 0.21 & 0.21 & 0.2 \\
\hline \multirow{2}{*}{ lpaved_ave } & $1.29 * *$ & 0.4 & -2.09 & -0.23 & -0.41 & -0.38 \\
\hline & 0.62 & 0.42 & 2.03 & 0.52 & 0.7 & 0.37 \\
\hline \multirow{2}{*}{ lpaved_min } & $0.71 * *$ & $0.44^{*}$ & 0.93 & $0.62 * *$ & $0.70 * *$ & 0.37 \\
\hline & 0.32 & 0.26 & 0.58 & 0.24 & 0.28 & 0.23 \\
\hline \multirow{2}{*}{ ltariff } & $-2.19 * *$ & $-6.04 * * *$ & 2.09 & $-9.61 * * *$ & $-2.83 * *$ & -1.44 \\
\hline & 0.99 & 1.99 & 8.46 & 3.39 & 1.29 & 1.23 \\
\hline \multirow{2}{*}{ ldocs } & $-5.53 *$ & 2.29 & 5.63 & $-5.25^{*}$ & $-7.82 *$ & $-8.11 * * *$ \\
\hline & 3.02 & 2.3 & 10.44 & 3.06 & 4.11 & 2.79 \\
\hline \multirow{2}{*}{ border } & $-0.48^{* *}$ & 0.04 & $2.14 * * *$ & -0.19 & $-0.74 * * *$ & $-0.40^{*}$ \\
\hline & 0.21 & 0.18 & 0.47 & 0.2 & 0.2 & 0.21 \\
\hline \multirow{2}{*}{ colony } & $0.67 * *$ & -0.21 & -0.35 & 0.37 & $0.59 *$ & 0.5 \\
\hline & 0.32 & 0.26 & 0.66 & 0.3 & 0.3 & 0.32 \\
\hline \multirow{2}{*}{ comlang_ethno } & $1.59 * * *$ & $1.31 * * *$ & -0.35 & $1.22 * * *$ & $0.93 * * *$ & $1.60 * * *$ \\
\hline & 0.37 & 0.27 & 0.8 & 0.3 & 0.29 & 0.35 \\
\hline \multirow{2}{*}{ constant } & $40.03 * * *$ & $20.82 * * *$ & 28.18 & $36.48 * * *$ & $54.98 * * *$ & $49.15 * * *$ \\
\hline & 9.78 & 6.24 & 37.93 & 8.02 & 14.45 & 7.21 \\
\hline Observations & 437 & 474 & 279 & 445 & 370 & 457 \\
\hline $\mathrm{R}^{2} /$ Pseudo $\mathrm{R}^{2}$ & 0.04 & 0.04 & 0.04 & 0.05 & 0.04 & 0.05 \\
\hline Model F/ $\chi^{2}$ & $1516.44 * * *$ & $2397.91 * * *$ & & $2324.02 * * *$ & $2621.91 * * *$ & $2726.26 * * *$ \\
\hline \multicolumn{7}{|c|}{$\begin{array}{l}\text { a. All models are NB2 and include fixed effects by exporter and importer. Dependent variable is trade0. } \\
\text { b. Robust standard errors (adjusted for clustering by country-pair) are in italics. } \\
\text { c. Statistical significance at the } 10 \%, 5 \% \text { and } 1 \% \text { levels is indicated by } * * * \text { and } * * * \text { respectively. }\end{array}$} \\
\hline
\end{tabular}


trade determinants (cf. Carrère 2006) leads to paved_ave and docs entering with unexpected signs, although both estimated coefficients are statistically insignificant (column 3). ${ }^{14}$ Paved_min remains significant at the 5\% level, although its magnitude is reduced to 0.25 . Overall, we conclude that our main findings are robust, in particular the importance of road infrastructure bottlenecks as captured by paved_min.

Finally, we present results disaggregated by BEC sectors 1-6 (Table 4). As expected, coefficient estimates vary considerably across sectors. This is due to two factors. Firstly, it follows from (3) that the reduced form parameters will vary with the elasticity of substitution. Secondly, trade flows in different sectors may themselves be more or less sensitive to particular factors, due to certain product characteristics such as unit value, perishability and bulk.

In terms of our road quality variables, Table 4 shows that the impact of paved_min is uniformly positive across sectors and is of comparable magnitude to our core elasticity estimate of 0.6 (Table 2 column 7). Paved_ave, on the other hand, displays much greater variation, and is not significant in most cases. Taking results for the two coefficients together, we conclude that trade flows in food, fuel, capital goods and transport equipment are particularly sensitive to road network quality, whereas industrial supplies and consumer goods are less so. Industrial supplies and capital goods are particularly sensitive to tariffs, while improved trade facilitation seems to be relatively important for food, transport equipment and consumer goods.

In sum, the above results disclose strong and consistent evidence to the effect that road network quality affects intraregional trade in ECA. We find that both the average and minimum levels of quality across transit countries are important, but our result is clearest in terms of the latter. We interpret this as suggesting that bottleneck effects and, by corollary, cross-country spillovers are important factors in determining intraregional trade. These results withstand numerous robustness checks, as well as estimation by individual sector (subject to cross-sectoral differences in the estimated elasticities of most variables).

\section{Policy Simulations}

For the remainder of this paper, we will concentrate on the NB2 results reported in column 7 of Table 2. According to those results, the marginal impact of tariff reductions and trade facilitation would appear to be much stronger than for improved roads, since the estimated elasticities are greater in absolute value. However, it would be unwise to draw policy conclusions from such an analysis. As 
is clear from the way the two paved roads variables are constructed, the relationship between bilateral road quality and the percent of paved roads in any given country is a complex one. It depends on overland transit routes, and on the quality of road infrastructure in transit countries. More important than the results from simply shocking either aggregate variable, is to trace through the impact of a change in individual country indices, allowing for transit effects. ${ }^{15}$

We deal with these difficulties through simulations (cf. Wilson et al. 2005). We define four counterfactuals in terms of particular changes to national policies. Following this, we use our gravity model elasticities to estimate the resulting change in intraregional trade flows. We are conscious of the limits of this approach, in particular to the extent that it assumes parameter constancy across policy shifts and treats each policy change in isolation from the others. Our simulation results should therefore be taken as indicative of the orders of magnitude involved only. Given the scope of this research, our simulation results do not measure economic welfare, but focus exclusively on projected trade impacts. Nonetheless, comparison of results across simulations is likely to prove a useful tool in assessing different policy options.

We therefore identify two initial policy simulations:

I. Road networks in all ECA countries are upgraded to the regional mean level of quality, namely $74.52 \%$ of paved roads; and

II. Road networks in Albania, Hungary and Romania only are upgraded as in I.

The motivation for these simulations is that raising each country's level of road network quality to the currently prevailing regional average represents an ambitious but feasible scenario. Concretely, this means that under Simulation I, 13 out of 27 ECA countries receive an upgrade, while under Simulation II it is limited to only the three countries identified above as connected with $65 \%$ of minimum quality routes in the region.

We conduct the simulations as follows. First, we set up the policy shock by recalculating both weighted average and minimum quality measures for all intercountry routes, in exactly the same way as described in Section 3 . The only difference is that country scores below the regional average are increased to that level before recalculation. Next, we calculate the resulting percentage changes in paved_ave and paved_min. Using our trade data and our estimated elasticities (0.79 and 0.60

\footnotetext{
${ }^{15}$ This complexity, which stems from the influence of multiple countries in terms of our quality indices, also has an important benefit in terms of exogeneity of our policy variables: given that transit countries are not involved in a bilateral trading relationship between a given exporter-importer pair, the risk that road quality is endogenous to bilateral trade is small.
} 
Table 5. Simulation results (increase in aggregate intra-regional trade) using estimated coefficients from Table 3 column 7

\begin{tabular}{lcc}
\hline & US\$bn & \% of baseline \\
\hline Simulation I (region wide road upgrade) & 56.71 & 50.4 \\
Simulation II (3 country road upgrade) & 34.99 & 31.07 \\
Simulation III (tariff reduction) & 6.19 & 6.38 \\
Simulation IV (trade facilitation) & 19.02 & 17.56 \\
\hline
\end{tabular}

Implied baselines are slightly different across simulations due to rounding and variations in effective sample size.

respectively), we then map these policy shocks to changes in bilateral trade values. Finally, we sum estimated bilateral trade impacts across countries to give the estimated overall increase in intraregional trade.

Results in Table 5 show that the potential trade gains from an ambitious but feasible program of road upgrades are large: of the order of $50 \%$ of baseline trade, or just over US $\$ 55$ billion based on total intra-regional trade in 2003. These figures do not include any flow-on effects to extra-regional trade. We therefore consider that our results lie towards the lower bound of expected total trade benefits from a road network upgrade.

A comparison of results from Simulations I and II also makes clear the crucial role played by just three countries in driving the above estimates. Focusing a road upgrading program of similar ambition on Albania, Hungary and Romania could bring intra-regional trade benefits equal to over $50 \%$ of those projected from the region-wide program in Simulation I. These benefits are not confined to the three countries receiving upgrades, but include strong spillovers to other countries in the region. Given the significant cost reduction likely to result from focusing infrastructure investments on three countries rather than 13-a point to which we return below - the expected return on investment from such a focused program is likely to be impressive from a regional point of view.

To provide a comparative context for the above results, we also conduct simulations designed to assess the projected trade impacts of policy changes affecting applied tariffs and trade facilitation (export/import documents):

III. Applied tariffs in all ECA countries are cut such that no tariff above the regional mean of $8 \%$ ad valorem is applied; and

IV. The numbers of documents required to export and import are reduced to their regional means, namely 8 and 12 respectively.

We regard these counterfactuals as representing ambitious but feasible reform 
programs in terms of tariffs and trade facilitation. On a substantive level (if not a formal one), we consider them to be comparable in scope to the road network upgrade analyzed above.

Results for both simulations are again reported in Table 5. It is notable that the increases in intra-regional trade associated with region-wide improvements in both traditional and "new" trade policies are considerably lower than for a road upgrade program conducted on a comparable scale. Trade flow changes from the tariff scenario are in the region of $6 \%$-nearly an order of magnitude smaller than the trade increases that flow from an infrastructure upgrade. ${ }^{16}$ The impact of trade facilitation measures is, however, considerably stronger than for a tariff reduction, of the order of $20 \%$ of baseline trade. It is still small relative to the gains from a road upgrade, even if it is focused on just three countries.

\subsection{The Cost Dimension}

The policy simulations discussed here focus exclusively on the intraregional trade benefits that could be expected from the different policy options under consideration. However, in order to make a balanced assessment of those options, we also need information on costs. This is particularly true when one of the options-an infrastructure upgrade - has much higher direct costs than do the others.

Our purpose here is not to provide a detailed cost breakdown of the type that would be required before undertaking a specific road upgrade project. Our analysis has taken place at a higher level of generality, and in particular has not considered the state of individual road arcs. For that reason, our assessment of the costs will focus on producing a general estimate only (cf. the more detailed approach of Buys et al. 2006).

Our starting point is the World Bank's ROad Costs Knowledge System (ROCKS), a standardized database of costs associated with various types of road works. ${ }^{17}$ It classifies individual projects by country and type of work, and allows the user to obtain cost per km information in a common (real) currency. Most database entries also include extensive additional information as to the tasks performed, as well as geographical conditions that can be expected to affect costs.

Since we do not have information on the exact work that would need to be per-

\footnotetext{
${ }^{16}$ Since we do not have data on quantitative restrictions and other measures that might restrain trade following a tariff cut, we would argue that this estimate is, if anything, on the high side.

${ }^{17}$ ROCKS can be downloaded from http://www.worldbank.org/transport/roads/rd_tools/rocks_main.htm.
} 
formed on each road arc in order to bring it up to the level of quality assumed in our counterfactuals, we simply assume that all arcs in countries undergoing an upgrade would require "development" or "reconstruction" work in terms of the ROCKS classification. This includes partial and full widening and/or reconstruction work, along with improvements to the road surface. The types of work that we are considering lie towards the high end of the full range of unit costs in ROCKS (excluding those relating to entirely new construction projects).

We use ROCKS to identify a range of ECA unit costs for such work running from around $\$ 36,000$ per $\mathrm{km}$ to $\$ 666,000$ per $\mathrm{km}$, with an average of approximately $\$ 269,000$ per $\mathrm{km}$. Taking the length of road to be upgraded in each country as the total length of arcs passing through that country as per our computerized map, we can make some simple cost estimates. ${ }^{18}$ Simulation I (i.e., a 13 country upgrade) would involve total up front costs of the order of $\$ 8 \mathrm{bn}$ (range based on minimum and maximum ROCKS unit costs: $\$ 1$ bn to $\$ 20 \mathrm{bn}$ ). Simulation II would cost around $\$ 3 \mathrm{bn}$ (range: $\$ 0.4 \mathrm{bn}$ to $\$ 8 \mathrm{bn}$ ). The intraregional trade benefits strongly outweigh the costs in both cases, to the tune of $\$ 45 \mathrm{bn}$ and $\$ 30 \mathrm{bn}$ respectively (ranges: \$37bn to \$56bn, and \$27bn to \$35bn).

\section{Conclusions and Directions for Further Research}

In this paper, we have built on and extended recent work by Buys et al. (2006) to show that an ambitious but feasible road upgrade program in ECA has great potential to boost intra-regional trade—-by as much as $50 \%$. Moreover, it is possible for the region to reap a large proportion of the overall gains by focusing attention on just three countries which are important transit corridors but exhibit significant limitations in terms of infrastructure quality: Albania, Hungary and Romania. Such a concentrated program of road upgrading would come at significantly reduced cost (perhaps $40 \%$ ) compared with attaining the same level of road quality on a region-wide basis, yet would bring around $60 \%$ of the total expected trade benefits.

The results we have presented suggest a number of considerations for policy in this area. Firstly, road quality and infrastructure clearly matter for trade in the ECA region. In quantitative terms, our simulation results suggest that a feasible but ambitious scenario of road upgrading is likely to bring greater intraregional trade benefits than comparable policy actions affecting either tariffs or customs procedures.

\footnotetext{
${ }^{18}$ We emphasize that these estimates are not based on upgrading the whole road network in each country, but only that part of it linking cities with population greater than 300,000 people.
} 
In any case, the combined impact of upgrading road network quality and improving trade facilitation appears likely to produce gains well in excess of those that could be expected from comparable tariff reductions. This result aligns well with the recent literature on trade facilitation using CGE models, which suggests that the expected gains from such measures may indeed be of greater quantitative significance than those from liberalization of "traditional" trade policy measures (e.g., Hertel and Keeney 2006). It is also consistent with other recent work that has shown the importance of transit country conditions, in particular in the Central Asia region (Grigoriou 2006).

A second important policy implication is that once transit is taken into account, infrastructure projects can have important intraregional spillovers. This dynamic does not generally operate in the same way for traditional trade policy measures, such as tariff cuts. Spillovers therefore need to be taken into account when assessing costs and benefits of various options for trade facilitation and development assistance strategies. They may support an argument for regional coordination and shared funding responsibilities for infrastructure projects (see Schiff and Winters 2002 for a review of the issues involved). In the present case, that suggestion takes on particular importance in light of the fact that Hungary is now a member of the EU, while Romania is soon to be such. Future allocation of EU funds could benefit from taking account of potential trade impacts not only nationally, but also through those countries' regional links.

A final policy message to highlight given our results is that the trade benefits from infrastructure upgrades can be obtained by countries acting unilaterally, or through regional cooperation. As is the case for many policy measures under the broad heading of trade facilitation, it is not necessary to wait for multilateral agreement before taking action to bring about greater integration into the trading system. Indeed, national and regional trade facilitation programs sponsored by the World Bank, regional development banks, bilateral donors, and public-private partnerships, for example, could be seen as important ways in which countries and regions can position themselves to reap maximum benefit from future rounds of multilateral liberalization.

While our results are highly suggestive in policy terms, there nonetheless remain a number of important research questions to be considered in future work. The trade facilitation literature has shown that according to country circumstances, the various modes of transport-road, rail, sea and air-can all be important determinants of trade performance (e.g., Wilson et al. 2005). Future research could usefully focus on the 
relative benefits and costs of upgrading infrastructure quality for each mode. As there is likely to be considerable variance in results across countries, regions and even sectors, it will be necessary to take a detailed approach to these questions, inclu- ding through an attempt to account for the interactions amongst the different modes. Increased availability of computerized maps means that it should be possible for future research to apply to other modes (e.g., rail) the same network-based approach to distance measurement and quality index weighting that we have used here for roads.

Our paper has focused exclusively on intra-regional trade. It will be important in future work to consider in addition the impacts of infrastructure upgrades on extraregional trade. To do this, it will be necessary to compile a detailed dataset that interfaces road and international air or sea routes, taking account of the location of principal sea and air ports. It will also be important to take account of possible trade creation or diversion effects. By helping move towards a more complete picture of the benefits of infrastructure upgrades, such an exercise would provide important additional information for policymakers.

Finally, the available data have not allowed us to pay detailed attention to the state of upkeep of particular road links. We have had to rely on national aggregates in assessing the extent to which network quality matters for trade. The flipside of this is that our cost estimate does not take account of the detailed work needed as part of a concrete upgrade program. There is thus considerable scope for additional work on specific cost-benefit analyses in this area.

\section{Acknowledgements}

We are grateful for financial support from a trade facilitation and development Trust Fund of the U.K. Department for International Development. Sincere thanks to Piet Buys, Uwe Deichmann and David Wheeler (World Bank) for their advice and assistance with the data and analytical framework, and to Yu Cheng Kuo for helping with compiling the road distance database. We are also grateful to Andreas Kopp (OECD), Henry Kerali, Bernard Hoekman, Beata Smarzynska Javorcik, David Cieslikowski, Tsukasa Hattori, Leonardo Iacovone and Souleymane Coulibaly (World Bank) for their comments and suggestions, as well as to seminar partici- pants in Washington, D.C. and Berlin. An anonymous referee also made some very helpful suggestions. Ayako Suzuki and Witold Czubala provided expert research assistance.

The findings, interpretations, and conclusions expressed in this paper are entirely those of the authors. They do not necessarily represent the view of the World Bank, 
its Executive Directors, or the countries they represent.

Received 25 January 2007, Accepted 27 February 2007

\section{References}

Anderson, J.E., Van Wincoop, E. (2003) Gravity with Gravitas: A Solution to the Border Puzzle, American Economic Review, 93(1), 170-192.

Anderson, J.E., Van Wincoop, E. (2004) Trade Costs, Journal of Economic Literature, 42(3), 691-751.

Asian Development Bank (ADB) (2006) Central Asia: Increasing Gains from Trade Through Regional Cooperation in Trade Policy, Transport and Customs Transit, ADB, Manila.

Baldwin, R.E., Taglioni, D. (2006) Gravity for Dummies and Dummies for Gravity Equations, Working Paper 12516, National Bureau of Economic Research, Cambridge, MA.

Bougheas, S., Demetriades, P.O., Morgenroth, E.L.W. (1999) Infrastructure, Transport Costs and Trade, Journal of International Economics, 47(1), 169-189.

Bougheas, S., Demetriades, P.O., Morgenroth, E.L.W. (2003) International Aspects of Public Infrastructure Investment, Canadian Journal of Economics, 36(4), 884-910.

Buys, P., Diechmann, U., Wheeler, D. (2006) Road Network Upgrading and Overland Trade Expansion in Sub-Saharan Africa, Working Paper 4097, World Bank, Washington, D.C.

Grigoriou, C. (2006) Landlockedness, Infrastructure and Transit Arrangements: New Estimates for Central Asian Trade, Working Paper (forthcoming), World Bank, Washington, D.C.

Cameron, A.C., Trivedi, P.K. (2001) Essentials of Count Data Regression, in A Companion to Theoretical Econometrics edited by Baltagi, B.H., Blackwell, Malden, MA.

Carrère, C. (2006) Revisiting the Effects of Regional Trade Agreements on Trade Flows with Proper Specification of the Gravity Model, European Economic Review, 50(2), 223-247.

Coulibaly, S., Fontagné, L. (2006) South-South Trade: Geography Matters. Journal of African Economies, 15(2), 313-341.

Cravino, J., Lederman, D., Olarreaga, M. (2006) Substitution Between Foreign Capital in China, India, the Rest of the World and Latin America: Much Ado About Nothing? Working Paper, World Bank, Washington, D.C.

Davidson, R., MacKinnon, J.G. (2004) Econometric Theory and Methods, Oxford University Press, New York, N.Y.

Disdier, A.C., Head, K. (2005) The Puzzling Persistence of the Distance Effect on Bilateral Trade, Working Paper, Sauder Business School, University of British Columbia.

Djankov, S., Freund, C., Pham, C.S. (2006) Trading on Time, Working Paper 3909, World Bank, Washington, D.C. 
Egger, H., Falkinger, J. (2006) The Role of Public Infrastructure and Subsidies for Firm Location and International Outsourcing, European Economic Review, 50(8), 19932015.

Francois, J., Manchin, M. (2006) Institutional Quality, Infrastructure and the Propensity to Export, Working Paper, World Bank, Washington, D.C.

Heckman, J.J. (1979) Sample Selection Bias as a Specification Error, Econometrica, 47(1), 153-161.

Helpman, E., Melitz, M., Rubinstein, Y. (2007) Estimating Trade Flows: Trading Partners and Trading Volumes, Working Paper, Harvard University, Cambridge, MA.

Hertel, T.W., Keeney, R. (2006) What is at Stake, in Agricultural Trade Reform and the Doha Development Agenda, edited by Anderson, K., Martin, W., World Bank, Washington, D.C.

Limão, N., Venables, A. (2001) Infrastructure, Geographical Disadvantage, Transport Costs and Trade, World Bank Economic Review, 15(3), 451-479.

Mayer, T., Zignago, S. (2006) Notes on CEPII's Distance Measures, Working Paper, Centre d'Etudes Prospectives et d'Informations Internationales, Paris.

Molnar, E., Ojala, L. (2003) Transport and Trade Facilitation Issues in the CIS 7, Kazakhstan and Turkmenistan, Working Paper, World Bank, Washington, D.C.

Nordås, H.K., Piermartini, R. (2004) Infrastructure and Trade, Staff Working Paper ERSD-2004-04, World Trade Organization, Geneva.

Nordås, H.K., Pinali, E., Geloso Grosso, M. (2006) Logistics and Time as a Trade Barrier, Working Paper TD/TC/WP(2006)3/FINAL, OECD, Paris.

Raballand, G. (2003) Determinants of the Negative Impact of Being Landlocked on Trade: An Empirical Investigation Through the Central Asian Case, Comparative Economic Studies, 45(4), 520-536.

Santos Silva, J.M.C., Tenreyro, S. (2006) The Log of Gravity, Review of Economics and Statistics, 88(4), 641-658.

Schiff, M., Winters, L.A. (2002) Regional Cooperation, and the Role of International Organizations and Regional Integration, Working Paper 2872, World Bank, Washington, D.C.

Soloaga, I., Wilson, J.S., Mejía, A. (2006) Moving Forward Faster: Trade Facilitation Reform and Mexican Competitiveness, Working Paper 3953, World Bank, Washington, D.C.

Wilson, J.S., Mann, C.L., Otsuki, T. (2005) Assessing the Benefits of Trade Facilitation: A Global Perspective, The World Economy, 28(6), 841-871.

World Bank (2006) Doing Business in 2006: Creating Jobs, World Bank, Washington, D.C. 